\title{
National Association for People Abused in Childhood (NAPAC)
}

\author{
Susan Quilliam
}

Freelance Writer, Broadcaster and Agony Aunt, Cambridge, UK

\section{Correspondence to Ms Susan Quilliam; susan@susanquilliam.com}

Received 8 October 2010 Accepted 14 October 2010

\section{What's your mission?}

The National Association for People Abused in Childhood (NAPAC) is a national charity that supports people who have suffered any form of childhood abuse, including sexual abuse. Until the establishment of NAPAC in 1997 there was no national body to support adults who had been abused in childhood. Since then, NAPAC has developed into a still-unique organisation with four full-time and 10 part-time staff and 40 volunteers who provide a national freephone support line, as well as an e-mail and letter answering service.

\section{How did you start?}

The charity was originally set up by Pete Saunders, an adult survivor of childhood abuse, who was unable to find any support for himself and so became determined to try and fill what turned out to be a huge 'gap in the market'. Pete, who is today the CEO of NAPAC, was quickly joined by many others keen to break the isolation and secrecy that surrounds this massive social problem.

\section{Who is your typical client?}

NAPAC's service users come from every kind of background, as abuse crosses all socioeconomic, cultural and ethnic boundaries. In the UK alone, the exact number of adults affected is unknown, but is estimated to be around 10-12 million. The media tend to focus on the cases that involve social services, so it is easy to overlook the fact that most abuse is perpetrated by someone very close to the child (e.g. family members, male and female, trusted professionals such as priests and so on). In adulthood, survivors can suffer very low self-esteem, feel dirty, ashamed and guilty, and struggle to trust others or form relationships.

What do you actually do? Can you tell us about a typical day?

Through the e-mail and letter answering service and national freephone support line, our trained volunteers offer a nonjudgmental, safe space for survivors to talk in confidence, often for the first time in decades. Service users are never told what to do, but instead are encouraged to take back the control stolen by the abuser so they can begin to move on. We can also help callers access further support, if desired. NAPAC is often just a first port of call for many survivors, who will then go on to receive much-needed counselling support.

Fortunately there doesn't really seem to be a typical day at NAPAC. One day we're writing a fundraising appeal, the next it might be answering a heart-rending letter from a survivor. This week alone we've had a visit from the BBC, and our CEO has presented at an international conference in Chicago - there's never a dull moment!

\section{How do clients find you?}

NAPAC does not have the money to advertise, but is still becoming increasingly well known. Media articles and advice columns often mention us as a source of support. Our organisation is often invited to comment in the press on child protection issues, and as we have no close connection with the Government we are always happy to tell the truth as we see it. Our leaflets are distributed far and wide, through, for example the National Health Service (NHS), the Citizen's Advice Bureau (CAB) and prison notice boards. We also have a high profile on the Internet and come near the top of relevant searches for help. However, we are still quite a low-profile charity in terms of general awareness of our existence, and are always keen to reach out to more people.

\section{How do you fit in with other} organisations?

No other charity does what we do, either in the UK or globally, so we hold a unique 


\section{FURTHER INFORMATION}

$\begin{array}{ll}\text { Who: } & \text { National Association for People Abused in Childhood (NAPAC) } \\ \text { Where: } & \text { Unit 3.42, Canterbury Court, Kennington Park Business Centre, } \\ & 1-3 \text { Brixton Road, London SW9 6DE, UK } \\ \text { Contact: } & +44(0) 2031760560 \text { (office for administration/donations) } \\ \text { Telephone support line: } & \begin{array}{l}0800853330 \text { (freephone) } \\ \text { (Hours: Monday-Thursday 10:30-21:00. Friday 10:30-16:00) }\end{array} \\ \text { Email: } & \text { support@napac.org.uk } \\ \text { Website: } & \text { www.napac.org.uk }\end{array}$

position. However, we do have a strong relationship with a number of other related British charities including Samaritans, ChildLine, the NSPCC (National Society for the Prevention of Cruelty to Children), Mind and Victim Support.

\section{What are your biggest blocks to development?}

Like many charities, money is never in great supply. We are always very grateful for donations, as understandably animals, children and cancer sufferers usually come way ahead of adult survivors of child abuse when it comes to charitable giving. NAPAC isn't a sexy cause! However, right now, we are lucky enough to be financially sound, although we are starting to think hard about what will happen when our Lottery Grant runs out.

Another concern unique to us is being infiltrated by a perpetrator. Although we thoroughly check everyone who works with us, we still worry about a potential troublemaker joining our growing band of wonderful volunteers.

\section{What's been your biggest moment of triumph?}

There has been no single moment of triumph, but every day we receive feedback from people whose lives we have helped to improve, and there is no greater reward than this. We feel pleased to be helping break down the walls of silence that have enabled abuse to go unchecked for generations and hope that by enabling people to speak out we are helping to protect children today.

We don't really go in for special events, but recently we held a reception at the London Coliseum before and during a performance of Swan Lake by the Mikhailovsky Ballet. We raised over $£ 2000$ (still a lot of money to a little charity like ours), but just as importantly we got Esther Rantzen to host the evening and hopefully raised our profile to a new audience.

\section{What are your plans and hopes for the future?}

NAPAC has some exciting plans for the coming months. We are currently working with the prison service to provide an intervention for prisoners. Prisons are full of abuse survivors, and enabling inmates to come to terms with their past is a huge step towards genuine rehabilitation. We recently undertook training in HMP Manchester and it was very well received.

Shortly we also plan to launch a pilot scheme in London to provide support groups for survivors in the community.

Next year we would like to hold a major conference on supporting survivors, but as we have to work within limited resources, we may have to wait a little longer for that!

\section{Competing interests None.}

Provenance and peer review Commissioned; internally peer reviewed.

\section{Editor's note}

This article is one in a series of occasional articles on key health organisations worldwide. The Journal would be pleased to hear from other organisations, particularly those based outside the UK, which would like to be similarly profiled. 